\title{
Teología de la liberación y marxismo*
}

\section{Ignacio Ellacuría,}

Centro de Reflexión Teológica,

San Salvador, El Salvador.

\section{Marxismo y teología de la liberación en la Instrucción vaticana}

La acusación de la Instrucción (1984) sobre las graves desviaciones de cierta teología de la liberación, debidas al maxxismo, aunque no hacen justicia ni al marxismo ni a la teología de la liberación, advierten de ciertos peligros que han de tenerse en cuenta en la teología de la liberación, entendida ésta como pensamiento teológico y como movimiento eclesial.

\section{Comentario a la presentación del marxismo en la Instrucción}

El marxismo, que es caricaturizado en la Instrucción, no responde a lo que es sino a malformaciones del mismo en el campo de la teoría y de la praxis.

\subsection{Concepción tolalizante, filosófico-ideológica}

"El pensamiento de Marx constituye una concepción totalizante del mundo, en la cual numerosos dalos de observación y de análisis descriptivo son inlegrados en una estructura filosólico-ideológica, que impone la significación y la importancia relativa que se les reconoce" (Instrucción, VII,6).

- Ignacio Ellacuría escribió estas reflexiones -en forma de breves proposicionescomo base para una conferencia sobre "Teologla de la liberación y maxismo" que dictó en la UCA, en noviembre de 1985 . Nunca le dio tiempo para redactarlas en forma de texto, a pesar de su propio interés; pero, aun en su forma actual, pueden sea bien leídas y entendidas.

Se publica aquí el texto, tal como lo dejó I. Ellacuria. Para facilitar su lectura y comprensión sólo se han ariadido trulos y subutulos en los diversos apartados. Tras cada uno de ellos aparece una proposición fundamental, que es explicada y comentada en otras proposiciones señaladas con el signo ( + ), y éstas, a su vez, se encuentren ulteriormente explicadas y comentadas en otras proposiciones que siguen. 
+ El que el marxismo ofrezca una concepción totalizante del mundo no implica necesariamente que sea cerrada y que no se deje cuestionar y transformar por la realidad histórica.

+ La estructura marxista no es formalmente filosófico-ideológica, al menos en el Marx maduro y en muchos de los marxismos contemporaneos, sobre todo los que hacen hincapié en un análisis de la realidad económica y política.

+ Los datos de observación y de análisis descriptivo son los que dan paso a leyes y teorias de carácter científico, por más que éste sea provisorio, aunque las leyes y las teorlas influyan, a su vez, en la captación e interpretación de los datos.

\subsection{Ateísmo y dignidad de la persona}

"El ateísmo y la negación de la persona humana, de su libertad y de sus derechos, están en el centro de la concepción marxista" (VII, 9).

+ Es cierto que en el marxismo ortodoxo y dogmático se consideraria el ateísmo como adquisición científica y como parte importante del sistema teórico y práctico marxista (cfr. Lenin, Acerca de la religión, Moscú, 1974). Pero es también cierto que hay partes muy importantes del análisis marxista que nada tienen que ver con él, y marxistas teóricos y prácticos que no aceptan como científica la afímación de que Dios no existe.

+ Pero decir que la negación de la persona humana, de su libertad y de sus derechos esı́ en el centro de la concepción marxista es una afirmación ideologizada que no responde a la totalidad de los hechos:

Supone unas concepciones de la persona humana, de la libertad y de los derechos humanos, que son parciales e históricos.

Absolutiza algunos hechos de los marxismos reales sin hacer bo mismo y sacar las mismas conclusiones de algunos hechos, no accidentales y esporádicos, de la Iglesia.

+ Que el marxismo desconozca la naturaleza "espiritual" de la persona y, sobre todo, que esto conduzca a subordinarla totalmente a la colectividad y a negar los principios de una vida social y políuca conforme a la dignidad humana, son afirmaciones no del todo gratuitas, pero que toman expresiones y realizaciones exageradas, como si fueran necesarias y esenciales.

\subsection{Verdad y praxis}

"La concepción misma de la verdad en cuestión es la que se encuentra totalmente subvertida: se pretende que sólo hay verdad en y por la praxis partidaria" (VIII, 4).

+ El difícil problema de la relación dialéctica entre teoría y praxis está del todo 
simplificado en esta formulación y esa simplificación lleva a su desnaturalización.

+ Por praxis se entiende a veces en el marxismo la plena actividad sensorial, y aun la experimentación, sin las cuales no puede haber no sólo una teoria materialista, sino simplemente una teoría realista.

+ Por praxis se entiende también una actividad social transformadora, realizada desde una de las partes o clases en conflicto, y se explica su importancia para la teoria cuando se tratan de explicar los procesos históricos:

Esta es una formulación compleja que implica la elección del lugar más adecuado para captar la verdad no sólo de lo que ya es, sino de lo que debe ser, punto que va a ser esencial en la teologia de la liberación.

Aun reconociendo que la verdad no fluye mecánicamente de una praxis social y partidista o, mejor, parcial, y que a veces algunos marxismos y marxistas actúan mecanicistamente, de ba ớa parte está el peligro de instalación en un punto de vista parcial e interesado, que no se ha justificado ni limilado críticamente.

\subsection{Lucha de clases}

"La ley fundamental de la historia, que es la ley de la lucha de clases, implica que la sociedad está lundada sobre la violencia" (VII, 6).

+ Es cierto que el maxismo ha hecho ley fundamental de la marcha historica, al menos desde el surgimiento del capitalismo, la lucha de clases, pero este concepto de lucha de clases pretende apegarse lo más posible a la realidad:

"Por lo que a mí se refiere, no me cabe el mérito de haber descubierto la existencia de las clases en la sociedad modema ni la lucha entre ellas. Mucho antes que yo, algunos historiadores burgueses hablan expuesto ya el desarrollo histórico de esta lucha de clases y algunos economistas burgueses la anatomía económica de éstas. Lo que yo he aportado de nuevo ha sido demostrar: 1) que la existencia de las clases sólo va unida a determinadas formas hisboricas del desarrollo de la producción; 2) que la lucha de clases conduce necesariamente a la dictadura del proletariado; 3) que esta misma dictadura no es de por sf más que el tránsito hacia la abolición de todas las clases y hacia una sociedad sin clases" (Marx y Weydemeyer, 5 de marzo, 1852).

Es posible que una lectura inmediatista y empiricista de la lucha de clases la reduzca a una especie de odio y revanchismo entre personas o aun entre grupos sociales, y en esto se cae a veces por demagogia polltica. Pero si la lucha de clases es un intrumento teórico de análisis social, debe quedar, por lo mismo, libre de todo subjetivismo psicologista, sin negar por eso que en el 
movimiento de masas quepa la tentación fácil para suscitar el odio como fuerza revolucionaria.

Con todo, no puede dejarse de insistir en que Marx y el marxismo buscan una sociedad sin clases y que la lucha de clases no es más que la respuesta de la clase explotada a la violencia de la clase explotadora.

+ Que la sociedad está fundada sobre la violencia ni es una tesis exclusiva del marxismo ni es una tesis que refleje lo más esencial del marxismo:

No puede ignorarse el peso que tiene en los marxismos prácticos revolucionarios el uso de la violencia, pero tampoco puede descuidarse que esa violencia no es siempre armada y que en los clásicos (Engels) supone el rechazo del terrorismo.

Pero la violencia no sólo se da y hay que superarla, sino que es defendida por muchos y de muy diversas formas, no excluida la Iglesia en su práctica histórica y menos otras fuerzas sociales y políticas que no la rechazan, sino que hacen de ella parte esencial de su seguridad dominante.

\subsection{Materialismo histórico}

Aunque la Instrucción no hace mucho hincapié en el reduccionismo materialista histórico, que hace de lo económico lo determinante en úllima instancia de todo lo demás, especialmente de lo cultural y de lo religioso, es uno de los supuestos que maneja dicha Insirucción.

+ Este cuasi-silencio sobre este punto fundamental parecerfa ser un reconocimiento tácito de la importancia que tiene lo económico en el conjunto de la vida histórica y la vida personal.

+ Los autores marxistas no siempre reconocen la autonomía relativa de las distinlas esferas que se hacen presentes en lo histórico, aunque su práctica no es siempre consecuente con lo que formulan en teoría, pues dan a la lucha ideológica y política un papel a veces preponderante:

Referido este problema al caso concreto de la religión, una de las perspectivas dominantes sobre este punto se desprende del siguiente texto de Lenin: "El marxismo es materialismo. En calidad de tal es tan implacable enemigo de la religión como el materialismo de los enciclopedistas del siglo XVIII o el materialismo de Feuerbach. Esto es indudable. Pero el materialismo dialéctico de Marx y Engels va más lejos que los enciclopedistas y que Feuerbach pues aplica la filosolía materialista a la historia y a las ciencias sociales. Debemos luchar contra la religión. Esto es el abecé de todo materialismo y, por tanto, del marxismo. Pero el marxismo no es un matcrialismo que se detenga en el abecé. El marxismo va más allá. Afirna: Hay que saber luchar contra la religión, y para ello es necesario explicar desde el 
punto de vista materialista los orígenes de la fe y de la religión de las masas. La lucha contra la religión no puede limitarse ni reducirse a la prédica ideológica abstracta; hay que vincular esta lucha a la actividad práctica concreta del movimiento de clases, que tiende a eliminar las raíces sociales de la religión. ¿Por qué persiste la religión entre los sectores atrasados del proletariado urbano, entre las vastas capas semiproletarias y entre la masa campesina? Por la ignorancia del pueblo, responderán el progresista burgués, el radical o el materialista burgués. En consecuencia, jabajo la religión y viva el ateísmo!; la difusión de las concepciones ateistas es nuestra tarea principal. El marxista dice: No es cierto. Semejante opinión es una ficción cultural, burguesa, limitada. Semejante opinión no es profunda y explica las raíces de la religión de un modo no materialista sino idealista. En los parses capitalistas contemporáneos, estas raíces son, principalmente, sociales. La ráz más profunda de la religión en nuestros tiempos es la opresión social de las masas trabajadoras, su aparente impotencia total frente a las fuerzas ciegas del capitalismo, que cada día, cada hora, causa a los trabajadores sufrimientos y martirios mil veces más horrorosos y salvajes que cualquier acontecimiento extraordinario, como las guerras, los terremotos, etc. 'El miedo creó los dioses'. El miedo a la fuerza ciega del capital -ciega porque no puede ser prevista por las masas del pueblo- que a cada paso amenaza con aportar y aporta al proletariado o al pequefio propielario la perdición, la ruina 'inesperada', 'repentina', 'casual', convirtiéndolo en mendigo, en indigente, arrojándole a la prostitución, acarreándole la muerte por hambre: he ahí la raíz de la religión contemporánea que el materialista debe tener en cuenta antes que nada, y más que nada, si no quiere quedarse en aprendiz de materialista. Ningún folleto educativo será capaz de desarraigar la religión entre las masas aplastadas por los trabajos forzados del régimen capitalista, y que dependen de las fuerza ciegas y destructivas del capitalismo, mientras dichas masas no aprendan a luchar unidas y organizadas, de modo sistemático y consciente, contra esa raf́z de la religión, contra el dominio del capital en todas sus formas... La propaganda atea de la sociedad democrática debe estar subordinada a su tarea fundamental del desarrollo de la lucha de clases de las masas explotadas contra los explotadores" "'Actilud del partido obrero ante la religión", Lenin, Acerca de la religión, Moscú, 1974, pp. 2122).

Este texto fundamental, por un lado, insiste en el carácter puramente derivado e insuficente en sí mismo de lo ideológico y, por otro, insiste en el origen de la religión aclual y su suspensión efectiva por la lucha de clases y el derrocamiento del capitalismo. Lenin reconoce que la mejor forma para quitar la religión a las masas no es indoctrinándolas, sino haciéndolas participar conscientemente en la lucha de clases.

+ Desde este punto de vista algunas de las afirmaciones y algunos de los te- 
mores de la Instrucción no son exageraciones, aunque sf parcializaciones, pues no todo marxismo presenta estas posiciones leninistas. Por otro lado, Lenin no se refiere a toda religión en toda época, sino al origen y al papel de la religión en una sociedad capitalista.

\subsection{Elica y política}

El marxismo carecería del sentido objetivo de la ética y caería sobre todo en un amoralismo político por la aplicación del criterio fundamental de la lucha de clases. "De hecho, el carácter transcendente de la distinción entre el bien y el mal, principio de la moralidad, se encuentra implícitamente negado en la optica de la lucha de clases" (VIII, 9).

+ Una mirada reduccionista sobre el conjunto del marxismo sí descubre, sobre todo en la práctica, que muchas acciones pierden objetividad moral en sí mismas y se aceptan o rechazan según contribuyen a la lucha de clases entendida, a veces, como maniobra inmediata de toma del poder.

+ Sin embargo, el carácter profundamente moral del marxismo, tanto en el rechazo del mal social real intrinsecamente deshumanizador, como en la propuesla de un hombre nuevo y de una sociedad nueva, hacen que la acusación de amoralismo político, en sí misma y en comparación con otros sistemas, sea del todo parcial.

2. Comentario a la presentación de la teología de la liberación en la Instrucción

El marxismo, sobre todo el marxismo así entendido, de ninguna manera ejerce en la teología de la liberación "la función de un principio determinante" (VIII, 1).

\subsection{El principio determinante de la teología}

La tcología de la liberación en sus principales representantes teóricos y, o práclicos no hace del marxismo principio determinante de su pensamiento y de su acción.

+ Si por principio determinante se entiende algo que determina exclusiva o principalmente lo que la teología de la liberación piensa o hace, tal afirmación es falsa y queda contradicha no sólo por la declaración explícita de los encausados, sino por el análisis de sus obras tanto teóricas como prácticas:

Los autores últimamente más atacados (G. Gutiêrez, L. Boff, J. Sobrino) son en su intención y en sus realizaciones prueba fehaciente de que el marxismo no es principio deterninante de su produccción teológica.

Los casos que pueden darse de colaboración teórica o práctica con el 
marxismo no apoyan en general esas posiciones que la Instrucción condena, sino lo que hay de positivo en lo que ella ve como negativo.

+ Ciertamente hay en casi toda la leologla de la liberación una presencia directa o indirecta de elementos marxistas, pero el principio últimamente determinante es la fe tal como se expresa en el mensaje biblico, en la tradición de la Iglesia y tal como se regula por el magisterio.

\subsection{Los contenidos teokgicos fundamentales}

En concreto, la teología de la liberación en su conjunto no cae en los errores teológicos que la Instrucción le atribuye, por lo que carece de sentido atribuírselos — pues no existen-a la presencia dcterminante del marxismo.

+ No se tiende a identificar el reino de Dios y su devenir con el movimiento de liberación humana (IX, 3), aunque sí se subraya su unidad y su intrínseca conexión.

+ No se identifica a Dios y la historia, aunque si se arirma que hay una sola historia, pero no monofisitamente entendida. La historia profana y la historia de la salvación pueden distinguirse, incluso estructuralmente, pero no pueden separarse (IX, 3 y 4 ).

+ No se reduce la fe a fidelidad a la historia, la esperanza a la confianza en el futuro y la caridad a la opción por los pobres, pero sí se sostiene que la feesperanza-caridad deben incluir esos elementos (IX, 5).

+ El amor preferencial por los pobres no excluye a ninguna persona, pero, si ha de tener un signficado real, implica una parcialidad, una preferencia real, que debe reflejarse en ponerse con ellos, sobre todo en tanto que violentados, en busca, no de la destrucción de sus oponentes, sino de su conversión y tranformación (IX, 7).

+ No se reduce la Iglesia a una realidad sociológica, pero se trata de superar la trampa del dualismo, que busca la justificación en su caráctcr transcendente y que disculpa así sus fallos hisı́ricos (IX, 8).

+ La teología de la liberación no cae en "una amalgama ruinosa entre el pobre de la Escritura y el proletariado de Marx" (IX, 10), aunque no deja de reconocer los vínculos que pueda haber entre el pobre y el explotado económicamente y no deja de preguntarse cómo la fe que favorece al pobre puede concretizarse históricamente.

+ La Iglesia de los pobres o la Iglesia popular no es una Iglesia de clase que se reduce y subordina a una lucha revolucionaria, sino que es una Iglesia histórica, configurada preferencialmente desde los pobres y para los pobres (IX, 10-12).

+ La teología de la liberación no desacredila a priori las decisiones del ma- 
gisterio como pertenecientes a la clase de los opresores, aunque sí mantiene una vigilancia crítica sobre los intereses de clase que pueden o no influir consciente o inconscientemente en las decisiones de la jerarquía y en las formulaciones del magisterio, sin que esto implique juzgar de todo el contenido de verdad desde el éxito de un revolución política, aunque se tenga en cuenta siempre una cierta utopía histórica, lo más conforme posible con las características del reino de Dios $(X, 1-4)$. Desde esta perspectiva se valora la doctrina social de la Iglesia.

+ La teología de la liberación no hace de la dimensión política "la dimensión principal y exclusiva" en la lectura de la Sagrada Escritura, como lo demuestra el caudal de espiritualidad tcologal que se saca de ella, aunque considera que aquélla es una dimensión a la que siempre se debe atender para no caer en reduccionismos interesados $(\mathrm{X}, 5)$.

+ La teología de la liberación no cae en un absolutismo del mesianismo temporal, ni mucho menos desconoce o desvirtúa la divinidad de Jesús, ni el carácter específico de la liberación cristiana como liberación de todo pecado. De ninguna manera niega o sustituye el carácter salvílico de la muerte y resurreción de Jesús, de las que no hace una interpretación exclusivamente política $(X, 6$ 12), sino que acepta toda la Escritura y en ella acepta también la radical novedad del Nuevo Testamento sin por ello negar la validez del Antiguo.

+ La teología de la liberación no cae en una inversión de los símbolos sacramentales, pero sí hace hincapié en que la historicidad del símbolo es esencial a la encarnación de lo simbolizado (X, 14-16).

\section{Advertencias y peligros a tener en cuenta en la Instrucción}

No obstante, los errores y desviaciones que tiene la Instrucción, tanto respecto del marxismo como de la teología de la liberación, ésta última y, en su caso, el manxismo, deben preguntarse qué acciones suyas o planteamientos pueden dar esa impresión o eventualmente caer en esos errores.

\subsection{Peligros históricos del marxismo}

Por lo que loca al marxismo, en algunas de sus Cormas leóricas y, o prácLicas, es clara la no aceptación de la fe cristiana en lo que tiene de transcendente y expresamente teologal, y es clara también la tendencia a caer en exageraciones de sus propias afimnaciones manxistas, con lo que a veces no dan razón ni siquiera de la realidad histórica empíricamente constatada.

+ Por lo que toca a lo primero, hay que decir que marxismos del tipo leninista, tomados sistemálica y totalmente, no son conciliables con la fe cristiana, por más que contengan elementos nọ sólo conciliables, sino favorecedores de ésta.

+ Por lo que toca a lo segundo, no hay duda que el marxismo cae en errores tcóricos y prácticos que no son superados por su presunto carácter científico o 
por su opción revolucionaria de clase, y eso no solo en tiempos de Lenin o de Cayetano Carpio, sino permanentemente, lo cual obliga no sólo a la autocritica de los resultados, sino a la auto y hetero-crítica permanente de los principios.

\section{Advertencias a la teología de la liberación}

Por lo que toca a la teología de la liberación es importante no sólo no caer en los errores que la Instrucción le imputa, sino no dar impresión fundada de aparecer cayendo en ellos, antes al contrario, mostrar cómo sus formulaciones y sus prácticas renuevan profundamente lo esencial del mensaje cristiano.

+ Aunque en su conjunto y en sus principales representantes (teólogos, pastoralistas, jerarqula, comunidades de base) no puede aceptarse como mínimamente objetiva la Instrucción, puede aceptarse que ocasionalmente se ha caído en algunos de esos defectos y errores.

+ El problema de la manipulación objetiva, incluso salvadas las intenciones, y de las simplificaciones es un problema real, que no por ser común a todas las formas de vivir el cristianismo deja de afectar a la forma de vivir el cristianismo propia de la teologfa de la liberación.

+ La teologla de la liberación pretende ser una relectura total del mensaje cristiano, que salve tanto la transcendencia del mismo como su historicidad, to cual la obliga a un renovado esfuerzo de totalidad y de equilibrio que no son fáciles ante la urgencia de la liberación:

El subrayado excesivo de algunas partes puede ir en deterioro del todo de la fe.

La urgencia de la liberación histórica puede poner en descuido la watalidad de la liberación cristiana.

La gravedad de la sitwación presente puede oscurecer lo que son planteamientos a larga distancia.

+ En esto no bastan las solas intenciones, sino que han de buscarse realizaciones equilibradas que acaben imponiéndose en la Iglesia:

Se puede tener la intención de no ser parcial, pero serlo de hecho en los temas elegidos y en el modo de tratarlos. Lo mismo vale de enfoques pastorales y de formación.

Es importante la tarea de ser aceptado dentro de la Iglesia para que realmente ésta se transforme desde dentro con la mayor profundidad y extensión posible.

\section{El aporte del marxismo a la teología de la liberación}

El marxismo ha aportado de hecho elementos importantes a la teología de la 
liberación, tanto en lo que ésta tiene de teología estrictamente tal como en lo que tiene de movimiento eclesial, elementos que siguen siendo valiosos y que no conllevan necesariamente consigo la totalidad del marxismo ni, menos aún, las desviaciones que la Instrucción y la propaganda dentro y fuera de la Iglesia le atribuyen.

\section{Elementos positivos del marxismo para la teología de la liberación}

El análisis de la toología de la liberación, en su doble sentido teórico y práctico, muestra elementos, quizás transformados, del maxxismo que han posiblitado en buena medida su novedad y su coherencia.

\subsection{La pasiblidad del aporte marxista}

No se discute la posibilidad que esto ocurra, por cuanto los hechos demuestran esa posiblidad y porque casos similares se han dado en la historia - caso del aristotelismo, del platonismo, del existencialismo, del idealismo etc.- no sin peligros - por ejemplo, la institucionalización del papado como poder temporal- para la fe y para la vida cristiana.

+ Lo que se pretende es analizar qué, de hecho, en la teología de la liberación puede considerarse como contribución del marxismo, aunque éste a veces no hubiera sido más que ocasión para que se recuperara algo especfficamente cristiano que estaba olvidado o minusvalorado.

+ No se pretende, por tanto, la discusión teórica de si en ello se ha procedido ilógica o críticamente, ni si el marxismo está de acuerdo con la interpretación que de algunos aspectos suyos ha hecho la teología de la liberación.

\subsection{El aporte del marxismo en lo ético}

El aporte inicial es un aporte ético que obliga a comprometerse con la lucha contra la injusticia -que representa fundamentalmente el capitalismo- y que mantiene a la mayora de los pueblos y a la mayoría de las personas en cada pars en simación de inhumanidad absolutamente intolerable, en la certeza que esto se debe a causas históricas y que ello puede ser superado poniéndose del lado de los oprimidos.

\subsubsection{La vivencia de la injusticia social}

El momento inicial del marxismo, para nuestro análisis, es la vivencia de la injusticia social, entendida no como algo periférico y dependiente de la malicia de algunos hombres, sino como algo que determina esencialmente nuestra fase histórica.

+ Este momento de vivencia de la injusticia como el problema fudamental de nuestra situación 0 , al menos, como problema gravísismo, no es exclusivo del 
marxismo e incluso es algo esencial al mensaje revelado, especialmente el veterolestamentario.

+ Pero convertirlo en algo esencial de todo comportamiento moral y político es, en la actualidad latinoamericana, algo que el marxismo, sobre todo en sus formas prócicas revolucionarias, lo ha puesto muy de relieve.

+ Esta fundamental eticidad, por lo que toca a este aspecto, suscitó entre los cristianos un cierto sonrojo por lo que suponia de olvido de algo esencial a la fe y un cierto complejo de inferioridad al comparar el compromiso ético de los marxistas revolucionarios con los más pobres frente al compromiso, en el mejor de los casos puramente verbal y cauteloso $\rightarrow$ no riesgoso-, de los hombres de Iglesia.

\subsection{Compromiso histórico}

El compromiso ético-materialista daba sentido élico a la acción histórica y daba sentido histórico al compromiso ético.

+ La historia y la polílica aparecen como lugar privilegiado de realización personal y, en ese sentido, se convierten en lugar privilegiado de la ética, pues la transformación de lo que es malo en lo que debe ser no es ya un problema puramente tecnológico, sino algo que exige y multiplica las energías élicas.

+ Los que por su formación cristiana estaban preocupados de la dimensión ética ven la posibilidad de aunar la acción histórica con el perfeccionamiento ético, superando así el dualismo entre la realización personal y la realización histórica.

+ Se recupera asl el sentido unitario de la praxis ética, que busca la realización personal en la realización histórica y que impregna de profundo sentido ético (y religioso) la acción política.

\subsection{Interpretación material y pollitica del pobre}

El marxismo da un sentido materialista y político a la interpretación de los pobres que se hacla en la Iglesia, con lo cual se recupera, y aun pasa a primer plano, una dimensión esencial de la misma que estaba olvidada, mal valorada y mal enfocada.

+ No es que la teología de la liberación confunda los pobres con el proletariado, pero recupera, por influjo del marxismo, una dimensión esencial de la fe y de la Iglesia, al ver que los pobres no son sólo los desposeídos a los que hay que socorrer, sino los llamados a ocupar un lugar preferencial en la Iglesia y en la historia.

+ La espiritualización de la pobreza había acabado por mistificar y diluir la pobreza histórica y la pobreza evangélica, mientras que la recuperación del sentido histórico de los pobres vuelve a dar a la pobreza su dimensión integral. 


\subsubsection{El carácter histórico de la esperanza}

El marxismo recupera el carácter histórico de la esperanza y con ello dinamiza y plenifica la esperanza teologal, que se había convertido en algo inoperante o en algo evasivo.

+ El marxismo no es el único restaurador de la esperanza como elemento esencial de la vida humana y aun de la historia, pero lo es en grado sumo y, además, por exclusión de la esperanza transcendente, subraya más la esperanza inmanente e impulsa a hacer del hombre sujeto de la hisloria

+ El Dios de la promesa y de la esperanza, sin perder su carácter transcendente, se conviente en fuerza histórica que significa el reino y que, en parte, lo adelanta.

+ La convicción de que el proletariado triunfará y llevará a una sociedad más humana y más libre despierta el sentido de la utopfa eficaz que va rompiendo los límites y se va abriendo a algo siempre mayor.

\section{El aporte del marxismo en lo epistemoĺgico}

Un aporte más específico del marxismo a la teología de la liberación se da en el campo epistemológico, sobre todo desde lo que se ha venido en llamar el análisis marnista.

\subsection{La sospecha de ideologización en la teología}

El análisis marxista se toma, ante todo, como un elemento desideologizador que levanta la permanente sospecha que, tras muchas afurmaciones que pueden parecer neutras o permanentes, pueden esconderse intereses que favorecen a los poderes dominantes injuslos.

+ Aunque sea exagerada la afimación marxista que la religión como un todo y muchas de las afirmaciones religiosas no sean otra cosa que el reflejo ideológico invertido de una estructura social injusta, las sospechas de que pueda convertirse en esto, y que, de hecho, lo sea en parte, obliga a una relectura critica total que va desde la interpretación de la Biblia y de la tradición hasta la valoración del magisterio y de las posiciones eclesiásticas.

+ Esta sospecha no sólo va contra las aplicaciones directas y explícitas a los problemas sociales, sino incluso en relación con las formulaciones que aparecen estricla y exclusivamente religiosas.

+ Ambos aspectos llevan a la exigencia de una nueva teología que no sólo tenga en cuenta esta sospecha ideológica, sino que trate de realizar esa teologla desde aquellos presupuestos que permitan evadir esa sospecha. 


\subsection{El lugar adecuado para la teología}

El análisis marxista lleva a preguntarse por el lugar adecuado para hacer una toología desideologizada.

+ Si de lo que se trata es de desenmascarar unas expresiones ieológicas que, como culturales, responden sobre todo a los intereses de las clases dominantes, el lugar apropiado para hacerlo es ponerse en el lugar de las clases dominadas, en cuanto pretenden contradecir esa dominación.

+ Si de lo que se trata es de crear unas nuevas expresiones teológicas más inmunes a la ideologización, el lugar apropiado será el que patentice mejor las necesidades objetivas, tal como se aprecian desde las mayorias oprimidas.

+ Se llega así a una cierta convergencia entre el reconocimiento del proletariado como lugar óptimo de interprelación histórica y el reconocimiento del pobre como lugar óptimo de interpretación teológica, con lo cual se reconoce una relación, pero no una pura traslación: lo que el proletariado es para la interpretación histórica es el pobre para la intepretación teológica.

\section{La praxis correcta para la teología}

El análisis marxista lleva a preguntarse por la praxis correcta de la que tanto depende la teoria cortecta.

+ Aunque el marxismo no haya resuclto bien cuál y por qué una praxis sea correcta ni cómo dcbe rclacionarse la praxis y la teoria para que ambas sean corrcctas, el problema planteado es un problema que la teología de la liberación recoge como esencial para su mélodo.

+ La lcología de la liberación asumirá y tratará de justificar que sólo una praxis orientada por la liberación integral y hacia la liberación integral garantiza la plenitud y rectitud de una teología cristiana, sobre todo si ha de ser una teologia de la "liberación", sin que por ello sostenga que la praxis correcta sea condición suficiente para la teologia correcta.

\subsection{La importancia de lo económico}

El análisis marxista sostiene que sólo preguntándose por lo económico como estrucutra determinante de la historia y, en particular, de lo ideológico de la historia, sc está en condiciones objetivas para hacer un análisis correcto de la historia y de los distintos productos históricos.

+ Aunque se pueda cstar en desacuerdo con el absolutismo de lo econónico, no sostenido por los mejores marxistas, no hay duda de que se trata de una dimensión fudamental a la que sólo el marnismo ha dado la importancia debida.

+ Al pretender historizar la salvación, la teología de la liberación no puede 
menos de atender a este aspecto y a los instrumentos de análisis que el marxismo ha preparado y utilizado para esudiarlo.

\subsection{La lucha de clases como hipótesis heurística}

El análisis marxisla sostiene que no se puede dejar de lado, en delerminado estadio del desarrollo histórico, la lucha de clases como clave de interpretación histórica.

+ No se trata de absolutizar y universalizar indebidamente la lucha de clases, pero sí de utilizarla como una hipotesis y una herramienta de trabajo.

+ Aun a sabiendas que la lucha de clases no es sin más un hecho, sino una interpretación de los hechos, no por eso pierde su eficacia heurística, siempre que no se haga de ella un dogma ni se la aplique mecánicamente, puntos en los que no debe caer un marxismo que pretenda ser cienuffico.

\subsection{El método dialéctico}

En general, la atención no exclusiva al método dialéctico, del que se precia Marx en El capisal, incluso en lo que tiene de corrección a la dialéctica hegeliana, es algo que la teología de la liberación recibe del marxismo.

+ La teología tradicional está más influida por el método deductivo metafísico de Aristótcles y, más recientemente, por otros métodos, como el transcendental, el fenomenológico, etc.

+ El método dialéctico, sobre todo en lo que tiene de sano materialismo, de concepción unitaria y dinámica de la realidad e incluso de oposición de contrarios, es algo que se hace presente de forma no exclusiva y a veces no explicita en la teología de la liberación.

\subsection{El aporte del marxismo en lo filosófico}

Un tercer aporte importante del marxismo tiene que ver con perspectivas más filosoficas, en el sentido de interpretaciones de la realidad en cuanto tal.

\subsubsection{Valoración de la realidad histórica}

La valoración de la realidad histórica, como realidad por antonomasia, es un aporte sustancial a una teología de la liberación que vuelve sus ojos a la historia de la salvación.

+ Aunque el marxismo no sostenga, sino al contrario, que la historia sea el lugar por excelencia de la comunicación y revelación de Dios, mantiene que es el lugar por excelencia de la manifestación de la realidad, con lo cual abre perspectivas metafísicas para abrir la historia a Dios.

+ La historia de la salvación cobra aś un rango teológico que no tenía en la 
teología clásica:

Ciertamente, esta idea de la historia de la salvación es en sí plenamente bíblica y anterior al marxismo; más aún, su reentrada en la teología no se debe especílicamente al marxismo.

Pero el marxismo, a pesar de no reconocer una salvación transcendente, insiste sobremanera en la salvación hislórica y en ello no está lejos de la utopía veterotestamentaria.

\subsubsection{Recuperación de la materialidad}

La recuperación de la materialidad del hombre y de la materialidad de la historia no sólo es un antídoto contra falsos espiritualismos, sino que implica la recuperación de puntos esenciales de la fe cristiana.

+ Falsos espiritualismos y transcendentalismos llevan a desconocer la importancia del pecado histórico y, consecuentemente, a desconocer la importancia de la salvación histórica, con lo cual no sólo se mutila una dimensión esencial de la fe, sino que se es connivente con la injusticia y la dominación.

+ Aunque un reduccionismo materialista supone también una mutilación del hombre, de la historia y de la fe, un sano materialismo es exigencia fundamental de un realismo que quiera dar cuenta de lo que hay y de lo que es.

\subsubsection{Un hombre nuevo en una tierra nueva}

La pretensión conjunta para lograr un hombre nuevo y una tiena nueva para entrar de lleno en la historia, una vez superada la pre-historia del subdesarrollo y de la explotación y la lucha, abre nuevos horizontes a la praxis y a la teoria que impulsa la teología de la liberación.

+ El hombre nuevo, por su materialidad, no puede darse más que en una tierra nueva, y esa utopia es acercable si se van quitando y poniendo las condiciones para ella.

+ Se recupera así la utopía cristiana que se expresa en términos parecidos, pero que abandona su realización histórica por una concepción excesivamente pesimisla o pasivista del pecado original y de la debilidad humana.

\subsubsection{Carácter agonista de la existencia humana y cristiana}

La recuperación del carácter agonista del hombre y del cristiano se potencia con la concepción revolucionaria de la praxis marxista.

+ La lucha contra el mal y el pecado cobra nuevas dimensiones, al ser también una lucha histórica.

+ La idea de la cruz, del sufrimento y de la persecución, la idea del amor como 
entrega de la vida por los demás, vuclve a revalorizarse no sólo como dimensión religiosa transcendentc, sino como dimensión ética inmanente.

+ Se obliga así a un desenmascaramiento de la violencia desde la perspectiva de la justicia.

\section{Posiblidad de asumpción crílica y cristiana del marxismo}

Ninguno de estos elementos creativamente asumidos pone en peligro la fe cristiana, antes al contrario, todos y cada uno de ellos pucden servirla de distintos modos.

\subsection{Consonancias entre marxismo y tradición bíblico-cristiana}

Bien mirados, casi todos estos elementos tienen su contrapartida en elementos típicamente cristianos y muchos de ellos responden a una tradición bíblica que ha operado directa o indirectamente sobre el propio Marx y otros marxistas.

\subsubsection{Consonancias en lo ético}

Por lo que toca al aportc éuco, los puntos que el marxismo resalta coresponden, al menos en su formulación ideal, a puntos importantes del mensaje nсо y, o veterotestamentario.

+ La vivencia de la injusticia, entendida sobre todo como opresión del pobre, es algo esencial al mensaje bíblico y a lo mejor de la tradición profética.

+ La dimensión social de la ética personal y la dimensión ética de la acción política, aunque no expresan toda la moral cristiana, son parc esencial de ella.

+ La recuperación del "pobre" — en lo que sca debido al marxismo- para la eclesiología y la moral cristiana, sería un aporte transcendental.

+ Aunque la esperanza marxista pucde secularizar peligrosamente la esperanza cristiana, su historización recupera una dimensión importante del Dios futuro.

\subsubsection{Consonancias en lo epistemológico}

Por lo que toca al aporte cpistemológico, hay una cicrta connaturalidad con algunas perspectivas especílicamente cristianas.

+ No las palabras ni las confesiones de boca, sino las obras, son las que muestran la realidad de lo que se crec: "Si me falla el amor y la justicia me separo indefcctiblemente de tí, Dios mío, y mi adoración no es otra cosa que idolatría. Para crecr en tí, debo creer en el amor y en la justicia, y creer en esas cosas vale mil veces más que pronunciar tu Nombre" (cardenal Henry de Lubac, cilado por Juan Luis Scgundo, Teología de la liberación. Respuesta al cardenal Ratzinger, Madrid, 1985). 
+ Escoger como lugar preferencial, tanto para el trabajo teórico como práctico de los creyentes, el lugar de los oprimidos, vistos como pobres desde la fe, tiene profundas raíces biblicas, sobre todo en el Nucvo Testamento.

+ La relación de fe y obras, de incerpretación y realización, es también un planteamiento cristiano.

+ La importancia de lo económico, aunque en térninos no cientílicos, como oposición riqueza-pobreza, ricos-pobres, está prescnte en toda la escritura, que se percata empíricamente de la imporancia del problema incluso en la relación de los hombres con Dios.

\subsubsection{Consonancias en lo filosófico}

Por lo que toca al aponte filosófico, también se dan consonancias del aporte marxista con los planteamientos cristianos.

+ La historia de la salvación da de por sí un relieve extraordinario a la historia, cosa que, por ejemplo, no se da en la concepción griega de la realidad.

+ La cstructura dialéctica de la vida personal, y aun de la historia, está en el Nuevo Testamento y en el Antiguo Testamento, y no es exagcrado decir que ahí está una de las fuentes de la dialéctica hegeliana y, consecuentemente, de la marxista.

+ La matcrialidad del hombre es sostenida hasta la exagcración en el Antiguo Testamento, así como la materialidad de la historia y aun de la salvación; y aunque el Nuevo Testamento supone un notable esfuerzo de espiritualización, no por eso hay razón para abandonar esa dimensión materialista.

+ EL hombre nuevo y la ticrra nueva son temas básicos del mensaje cristiano.

+ Aunque la violencia uene difícil conjunción con lo esencial del mensaje cristiano, no por eso falta en la vocación cristiana un fuerte llamado a la existencia agonista.

+ Las dimensiones sociales y estructurales, así como colectivas, del pecado, lejos de ser extrañas al cristianismo, son de lo más tradicional en êl, aunque sin menoscabo de la dimensión personal del mismo.

\subsection{Realidad y posiblidad de asumpción crítica de elementos marxistas}

Ninguno de estos elementos está de suyo ligado a una concepción atea o atentatoria contra la dignidad del hombre y son plenamente desligables de principios marxistas que puedan considerarse inconciliables con la fe cristiana.

\subsubsection{El hecho real de la asumpción del marxismo}

Pudicra decirse que ninguno de esos elementos, así purificados, son es- 
pecificamente maxistas, por lo que la teologia de la liberación no habria tenido que recibirlos del marxismo.

$+\mathrm{El}$ hecho es que, aun no siendo posturas exclusivamente marxistas, y aun siendo préstamos críticamente asumidos, la teología de la liberación sobre lodo cono movimiento genérico eclesial, los ha revivido a la luz y al calor del marxismo.

+ Tal es asi que existe el peligro, por la semejanza no sólo de las apariencias, sino del fondo, de borrar las diferencias y pensar que se trata de lo mismo.

+ El marxismo opera aquí como una especie de medium in quo a veces y como medium quo otras, tanto en la teorla teológica como en la praxis teologal:

Como medium quo actúa cuando se convierte como en luz, sobre la que no cae directamente la mirada, pero con la que se ve lo que se busca.

Como medium in quo actúa cuando se lo toma como instrumental explícito tanto de mediación hermeneútica como de mediación social, cuando con su propia cientificidad -ajena a la fe-se le utiliza explícilamente.

\subsubsection{Posiblidad y realidad de la asumpción crítica del marxismo}

Nada de esto supone que la teología de la liberación tome como principio determinante de su quehacer el marxismo o que asuma, ni siquiera implícitamente, el marxismo como una totalidad sistemática a la que se subordina toda intelección y préctica de la fe.

+ La teología de la liberación en lodos sus mejores cultivadores teóricos y práclicos sitúa la fe por encima de todo sistema por muy científico que se le suponga.

+ De hecho, la teología de la liberación asume crítica y parcialmente los aportes marxistas y a veces sólo muy indirectamente.

+ Eslo no obsta a que no se vean riesgos en la accptación simplista y no crítica de interpretaciones y práclicas marxistas.

\subsubsection{Necesidad de la asumpción crítica del marxismo}

La afirmación de que el cristianismo no necesila acudir al maxismo para potenciarse como cristianismo es en sí equívoca y desconoce la tradición intelectual de la fe cristiana.

+ El cristianismo no recibe el dalo revelado del marxismo, como no lo recibe de ningún otro sistema.

+ Pero necesita inteligir la fe y dar razón de ella para lo cual si necesita del maxismo, al menos en lo que tiene de cuestionamiento. 


\section{El aporte de la teología de la liberación al marxismo}

Aunque la teología de la liberación y el marxismo no son dos instancias intercambiables y es más lógico el préstamo que ella hace del marxismo que el que éste haga de aquélla, sin embargo la teologia de la liberación está en capacidad para mejorar limitaciones y excesos tanto teóricos como prácticos del marxismo.

\section{Posibilidad del aporte de la teología de la liberación al marxismo}

La tcología de la liberación y el marxismo no son dos instancias intercambiables, aunque no por eso sean incomunicables.

\subsection{Diferencia formal entre teología de la liberación y marxismo}

La teologia de la liberación, aunque tiene su propia cientificidad, tanto en su teoría como en su práctica, su estatuto epistemológico y práctico es diferente del marxista.

+ Aunque la teología de la liberación tenga como principio determinante último la fe, no por eso deja de tener sus propias exigencias epistemológicas y sus referencias a la realidad, que le proprocionan una cierta razonabilidad у aun uла cierta cientificidad.

+ El marxismo a su vez no es sólo análisis científico, sino que es también praxis hislórica que puede estar orientada por leyes históricas, pero que necesita ouros aportes no dados por las leyes; es también una concepción general de la vida y de la historia:

En cuanto análisis cientúfico poco le puede aportar la teología de la liberación, si no es preguntas-realidad y horizontes utópicos y críticos, que pueden exigir reconversiones profundas, aunque intemas, del análisis.

En cuanto praxis consecuente, el marxismo deja muchos campos abiertos que la teología de la liberación, como elaboración de la fe desde una situación determinada, puede iluminar.

En cuanto concepción general, la teología de la liberación puede y, de hecho, presenta al marxismo cuestiones críticas, que tienden a romper todo sistematismo cerrado.

\subsection{Posibilidad de coexistencia entre teología de la liberación y marxismo}

La no intercambiabilidad hace que no puedan sustituirse mutuamente, pero no impiden que coexistan.

+ Si la teología de la liberación y el marxismo se toman como interpretaciones globales y últimas de la existencia, en cuanto tales, propenden a ser excluyentes, de tal manera que se es principal y unitariamente una cosa u otra. 
+ Si, en cambio, se opla por una de las dos interprelaciones como la última determinante de la propia existencia y de la visión de la realidad, entonces sc pucde tomar de la instancia subaltema clementos que pueden reasumirse en el sistema optado:

Podrá afimarse que entonces el clemento desglosado ya no cs marxista o cristiano, sino que pasa a ser lo que es el sistema en que se ha estructurado, pero esto mismo indica la posibildad y la utilidad del intercambio.

Pero la posibilidad de asumir elementos hecerogéncos, no siempre para bien, es algo no sólo posible, sino incvitable, como se ha demostrado en la historia.

2. Aporte de la teología de la liberación en la concepción general de la realidad

En el plano de la concepción gencral de la realidad, la teología de la liberación puede ofrecer "crcíblementc" algunos clementos esenciales a la concepción marxista.

\subsection{Apertura a la realidad de Dios}

Ni la idea de Dios ni la religión son puramente un reflcjo de una situación de explotación, ni menos aún son algo refutable en base a ningún materialismo cientílico.

+ La ciencia positiva nada puede decir cientílicamente en favor ni en contra de la existencia de Dios y es una irresponsabilidad científica afimar lo contrario.

+ La religión, y en concreto la le cristiana, por mucho que haya podido ser opio del pucblo, ni actual ni potencialmente se reduce a eso, como lo muestran los propios movimientos de liberación cristiana.

+ No sólo hay marxistas que sostienen que Dios y la fe cristiana no son incompatibles con lo más esencial del marxismo, sino que un Dios y una fc purificados de todo idolatrismo aparecen como horizonle utópico que rompe limilaciones de un sistcmatismo ccrrado:

El maxismo propende a divinizar la materia (cterna, infinita ctc.), al hombre y a la historia como autores y creadores de sí mismos, con lo cual abre a la matcria y al hombre sobre sus propios límites en un movimiento incesante hacia un más indefínido.

El cristianismo, tal como es desarrollado por la teología de la liberación, empieza reconociendo muy explícitamente la divinización del hombre y de la historia en virtud de un Dios que se ha limitado, pero para ir rompicndo los límiles por sucesivas negaciones. 


\subsection{Materialismo abierto}

El materialismo marxista, sin dejar de serlo, puede ser un materialismo abierto tanto por lo que toca al hombre como a la historia.

+ La teología de la liberación puede aceptar que todo cuanto se da en la historia humana es estrictamente material, por más que no sea exclusiva ni principalmente corporal, pero esto implica que tenga un concepto adecuado de materia y que esté atenta a todo lo que la materia puede dar de sí.

+ La materia humana y la materia histórica, al ser cualitativa y estructuralmente distintas de otras materias, están abiertas no sólo a pensamientos transcendentes, sino también, de algún modo, a realidades transcendentes:

Cerrar esa posiblidad no sólo es algo problemático y sin sólido fundamento, sino algo que cierra y limita al hombre.

Aunque el ateísmo marxista sirve para negar falsas imágenes de Dios y de la transcendencia no puede cerrarse a cualquier imagen posible, sobre todo si no entra en contradicción con sus propósitos lundamentales.

\section{Matización de lo económico como última instancia determinante}

Aunque la correcta teoría marxista no cae en simplificaciones mecánicas cuando habla de la infraestructura económica como última determinación de todo lo demás, la teología de la liberación puede salvarle del riesgo de unidimensionalidad o unidireccionalidad, pues, aceptando la delerminación que proviene de las instancias económico-sociales, mucstra, en su propio ejercicio, la autonomía relativa de otras instancias y eventualmente la preponderancia de éstas sobre aquéllas.

+ La teología de la liberación como práctica teórica y como movimiento práctico muestra no sólo su autonomía, sino también su capacidad para dar aportes especificos, tanto en lo teórico como en lo práctico.

+ La realidad no queda reflejada adecuadamente cuando todo se ve como determinado y, más aún, como originado en y por la infraestructura económica, lo cual la teología de la liberación lo reconoce equilibradamente sin irse por ello a ignorar culpablemente la importancia que tiene lo económico en el proceso hisbrico.

+ La crítica construcliva que puede hacer aquí la teología de la liberación enriquece al marxismo y pone freno a sus excesos.

\section{Aporte de la teología de la liberación en lo antropológico}

En el plano antropológico la teología de la liberación, sobre todo en lo que toca a la ética, puede aportar al marxismo elementos que, precisamente por no 
serle ajenos, pueden ser asimilados más fácilmente.

\subsection{La dimensión personal del hombre}

La dimensión personal del hombre debe ser acentuada sin menoscabo de la dimensión social e histórica, lo cual evitaría una politización absolula de la existencia humana.

+ El marxismo hace hincapié en la división entre el ámbito público y privado del hombre, pero descuida un tanto el ámbito privado y lo presiona con el ámbito público:

No basta con aceptar la separación teórica si la práctica deja debilitado el ámbito de lo privado e interpersonal.

Esto es válido, sobre todo, en las elapas previas al comunismo ideal, en las que el peso de lo estructural, en vez de disminuir, se acrecienta.

+ Aunque no puede ponerse el bien particular sobre el bien común ni los intereses individuales sobre los intereses generales, la teología de la liberación insiste en el valor absoluto de la persona humana:

La teología de la liberación supera el individualismo liberal y recupera la idea clásica del bien común y la idea bíblica del bien del pueblo.

Pero también insiste en la relación primaria del hombre con Dios que hace que toda persona sea irrepetible: a) la teología de la libcración no acepta que el hombre sea pura y totalmente resulcado de las relaciones sociales, b) es de suyo un principio de realizacion personal, condicionado, pero relativamente autónomo.

+ La absolutización de la dimensión política no sólo limita otras dimensiones esenciales del hombre, sino que lleva a la desviación totalitaria de la política:

El "todo es político" debe corregirse con "lo político no es todo" ni es, en cualquier caso y perspectiva, lo principal.

La teologia de la liberación, al subrayar dimensiones walales de liberación, rompe con el exclusivismo btalizante político sin por eso perderse en la atomización aditiva de las dimensiones humanas.

\subsection{Cambio y conversión personal}

El acento en el cambio de estructuras no puede olvidar el acento en el cambio de las personas.

+ La persona no es sin más resultado de las estructuras y, por consiguiente, no se perfecciona por efecto mecánico de las estructuras cambiadas, sobre lodo si el cambio afecta tan sólo a las estructuras socio-económicas. 
+ La llamada a la conversión personal, la espiritualidad, tal como la hace la teología de la liberación, se convierte en un aporte fundamental:

Esa conversión personal pretende ser wtal por cuanto la liberación no es sólo socio-economica, sino total.

El cultivo de la espiritualidad, tal como es entendida por la teologia de la liberación, no sólo plenifica, sino que orienta el cambio estructural.

+ La teologí de la liberación subraya que, además del hacer el bien, hay que ser bueno:

El hacer el bien en têrminos de praxis social tiene sus propios peligros deshumanizadores, aunque es la praxis correcla la que va configuando en buena medida el ser correcto.

Pero hay todo un orden de actiudes, de sentimientos, etc., que complementan la praxis correcta, al menos en el modo, y que, sobre todo, configuran moralmente la persona haciéndola buena.

\section{Radicalización de la realidad del pecado}

El tratamiento que del pecado hace la tcología de la liberación amplía y supera ciertos enfoques unilaterales del marxismo, como éste ha ayudado a superar otros enfoques unilaterales, vigentes en el cristianismo.

+ La ampliación del pecado histórico-social con el pecado natural-original y el pecado pesonal da un realismo al problema del mal que el marxismo habitualmente desconoce:

No todo el mal histórico se debe a la mala estructuración económica ni siquiera al abuso maléfico de las clases dominantes, sino que tiene raíces propias tanio en el carácter natural de la especie humana como en el carácier personal de cada subjetividad.

Aunque el mal histórico influye sobre lo natural y lo personal, también lo natural y lo personal influyen sobre lo histórico y sólo con su tratamiento propio - no separado - podrá enfocarse integralmente el problema del mal, incluso en su pura dimensión objetiva.

+ La referencia a Dios, historizado en Jesús, historiza a su vez el pecado sin relativizarlo y trivializarlo:

La norma fundamental de la moral en la tcología de la liberación, tanto en lo que no debe hacerse o serse como en lo que debe hacersc o serse es el Jesús histórico, en su modo de ser y de actuar, tal como hoy es vivificado por el Espiritu y contrastado por los signos de los tiempos.

Hay pues una norma, pero esta norma es histórica, de modo que, por un lado, tiene un cierto carácter absoluto obligante, sobre todo en lo que excluye, 
pero, por otro, tiene la flexiblidad que da la prioridad del espiritu innovador sobre la letra repelitiva.

Al poner el pecado contra el hombre en relerencia con Dios cobra su gravedad específica, que no abandona lo humano, sino que lo potencia y lo transcendentaliza ("lo que hicieron con uno de estos pequefios lo hicieron conmigo").

\subsection{Humanización de la lucha de clases y de la violencia}

La lucha de clases en sus múltiples variaciones históricas puede cobrar, a través de la teología de la liberación, mejoras sustanciales.

+ Ya la idea central accrca de la lucha de clases, que procede de un mal, que es un mal y que debe llevar ella misma a su propia superación, puede ser reforzada por la teología de la liberación en su aceptación realista de la lucha de clases:

Teóricamente, nada más opuesto a la lucha de clases que el marxismo, cuyo ideal utópico es no sólo la desaparición de la lucha, sino de las clases mismas a través del logro de una verdadera humanidad libre y solidaria.

Ese mismo ideal utópico puede verse en el reino de Dios o en los futuros mesiánicos de los profetas, donde deben desaparecer todas las desigualdades opresoras.

+ El peligro de identificar la lucha de clases con el odio de las personas puede ser corregido desde la tcología de la liberación:

La teología de la liberación mantiene con el marxismo la necesidad de una vigorosa lucha para terminar con la dominación de una clase por otra, con todas las consecuencias que trae esa dominación.

Pero sostienc que la lucha por la justicia puede hacerse desde el amor, por cuanto la historia vive del amor y va hacia el amor y no puede realizarse humanamente, sino en el amor.

La idea del amor universal, historizada en el amor preferencial por los pobres, junto con la vigorosa reclamación del hacer justicia bíblica, se constituye en una solución difíci, pero utópicamente válida

+ El recurso a la violencia es considerado como un mal, no siempre inevitable, pero que debe ser reducido al máximo y controlado:

Por su carácter cristiano, la teología de la liberación no es propensa a permilir el uso de la violencia, aunque su inspiración veterotestamentaria y su realismo social hacen que no se manifieste hipocritamente contra ella: a) conoce bien las legitimaciones que de la violencia ha hecho secularmente la Iglesia por motivos no evangélicos y conoce quién y cớno se desencadenan los procesos violentos; b) pero saca todas las consecuencias de la prioridad 
de la justicia y de la opción preferencial por los pobres.

+ Sin ser pacifista, la teología de la liberación propende a ultimar todos los recursos pacificos y, llegado cl uso de la violencia, procura humanizar el espiritu de quienes están inmersos en ella y las consecuencias de sus efectos: a) la misericordia y el perdón son virtudes que la teología de la liberación pretende aportar a las personas y a los procesos; b) el amor a los enemigos no oscurece su condición de adversarios, pero deja abierto el camino para la reconciliación.

\subsection{Negación de la absolutización de cualquier tipo de poder}

La teologia de la liberación enschia a relativizar o, mejor, a no absolutizar lo que no es realmente absoluto y sitúa cada cosa en la jerarquía que le corresponde.

+ El esquema del servicio al reino de Dios hace que desconfle de la absolutización de las organizaciones o de los partidos, que miran más por su propia consolidación y poder que por el bencficio de los más pobres:

Frente a otras teologías y prácticas eclesiales, la teología de la liberación no ve en la Iglesia como organización un fin en si mismo, sino algo puesto al servicio de algo que está fuera de ella; pretende superar al máximo diversas formas de burocratismo.

En la misma línea, está pronta a desautorizar prácticas políticas o concepciones que subordinan el bien popular al bien de la propia organización.

+ El esquema evangélico de servicio le hace poner por encima el servicio sobre la dominación y con ello pone en crisis el concepto de poder.

De nuevo, la teología de la liberación, al criticar la práctica eclesiástica del poder desde arriba, deja al descubierto y denuncia todo uso del poder en benclicio propio o en contra de quienes no están de acuerdo.

La ambición de poder es condenada como forma fundamental de dominación y tiende a ser superada por la entrega de la vida a los demás.

\subsection{Superación del reduccionismo del concepto de pobre}

La teología de la liberación trata de superar un concepto reduccionista de pobre, de modo que no admite la identificación sin más del pobre brblico con el proletariado.

+ La teología de la liberación mantiene que, al menos en las actuales circunstancias, el concepto biblico de pobre se realiza por antonomasia en el desposeído económicamente:

No admite la generalización unívoca y uniformante del concepto de pobreza, sino que reserva éstc para el pobre en sentido económico. 
En este sentido, no pretende desvirtuar la dimensión económica del problema de la pobreza.

+ Pero no admite que sólo el proletariado sea el sujeto principal de la liberación y, mucho menos, el destinatario principal de la misma:

Fuera de que en la experiencia en América Latina, sea por la importancia relativa del proletariado en muchos lugares, sea por el comportamiento del mismo, no constaba la importancia del proletariado, este no coincide con el pobre al concebirse en términos tomados de una determinada relación salarial: a) los pobres están en la escala económica por debajo de los prolelarios 0 , al menos, algunos de ellos y en gran número lo están; b) el proletariado de los países ricos adquiere respecto de los paises pobres caracteristicas de explotadores:

No se excluye que el proletariado sea sujeto principal de la liberación, pero no se acepta dogmáticamente que, por serlo, sea sujeto pleno de libereción ni que lo dejen de ser otros sectores desposeídos: a) la experiencia de campesinos e indígenas, como sujeto de cambio revolucionario, rompe con ciertos dogmatismos marxistas; b) la inspiración cristiana como motor de esperanza se hace sentir con caracteristicas propias que enriquecen al sujeto de la liberación.

Aunque el marxismo no sostiene que sea solo el proletariado el destinatario de la salvación, la teología de la liberación insiste, por un lado, en la universalidad de la misma y, por otro lado, en la preferencialidad de lodo pobre y no sólo del explotado en sentido tócnico.

\subsection{El carácter ético de la política}

La teología de la liberación insiste en el carácter ético de la política, de modo que somete ésta a aquél como norma, sin dejar de reconocer que la política admite a veces tan sólo un idealismo realista

+ Aunque la teología de la liberación mantiene una ctica propia, mucho més evangélica que iusnaturalista o legalista, no admite ninguna instancia de la vida que no sea sometida a los valores morales:

Esa ética busca la liberación total de todos los hombres, manteniendo distinciones jerárquicas tanto entre los diversos aspectos de la liberación camo entre los sujetos activos y pasivos de los mismos.

Pero a pesar del carácter histórico de esa liberación y de su tica correspondiente, admile y exige principios o inspiraciones normativas que superan el mero pragmatisno - los medios justificados sin más por los fines buence pretendidos - o la mera logica inmanente de la praxis. 
+ Aunque la teología de la liberación reconoce que son dos esferas distintas la ética personal y la ética política, no por eso admite que la esfera política no pueda ser orientada en algún modo por la inspiración evangélica:

La ética política no puede verse como una aplicación de la élica personal, porque en la políuca intervienen impersonalmente las personas y, además. tienen un papel preponderante las leyes estructurales.

Pero la ética política debe orientarse según valores y la teologia de la liberación los propone como ideales o como nomas intraspasables según los casos: a) tanto el Antiguo Testamento como el Nuevo Testamento apuntan a elementos esenciales de esa ética, cuando se los lee desde la perspectiva de la teologia de la liberación; b) la correlación múltiple liberación-salvación abre a aquélla y concretiza a ésta de múltiples formas: por ser una liberación salvadora, abre la praxis histórica y a los hombres en ella al ideal de la salvación plena; por ser una salvación liberadora, exige que la praxis de salvación pase por los condicionamientos materiales de la praxis histórica, sin permitir evasiones por el desvío de las buenas intenciones o de la buena voluntad.

+ Esto no obsta para que la teología de la liberación reconozca la necesaria ambigiledad de lo político, a la que, sin embargo, trata de purificar desde un horizonte utópico. 